УДК 316.733

\title{
КУЛЬТУРНЫЙ СДВИГ В РОССИЙСКОМ ОБЩЕСТВЕ
}

\section{Полотнянко Василий Сергеевич \\ студент}

Тедеева Людмила Николаевна

преподаватель

ФГБОУ ВО «Волгоградский государственный аграрный университет»

Аннотация: В данной статье рассматривается культурная диспропорция в развитии российского общества, как признак культурного сдвига. Констатируются причины внутренней бездуховности, как следствие феномена антикультурности. России, как и странам мира, угрожает упадок личной и государственной морали, глубокий распад абсолютных идеалов добра. Засилье технологической культуры, где нет место глубокому чувству миросозерцания, приводит к потребительскому эгоизму, безответственности и человеческой чёрствости.

Ключевые слова: культура, культурный сдвиг, духовная ценность, общество, молодежь, власть, идеократия, партократия, политическая система, СМИ, духовная культура, духовное развитие, технологическая культура.

\section{CULTURAL SHIFT IN RUSSIAN SOCIETY}

\section{Polotnyanko Vasily Sergeevich} Lyudmila Nikolaevna Tedeeva

\begin{abstract}
This article examines the cultural disparity in the development of Russian society as a sign of a cultural shift. The reasons for internal lack of spirituality, as a consequence of the phenomenon of anti-culture, are stated. Russia, as well as the countries of the world, is threatened by the decline of personal and state morality, a deep disintegration of the absolute ideals of good. The dominance of technological culture, where there is no place for a deep sense of worldview, leads to consumer selfishness, irresponsibility and human callousness.

Key words: culture, cultural shift, spiritual value, society, youth, government, ideocracy, partocracy, political system, mass media, spiritual culture, spiritual development, technological culture.
\end{abstract}




\section{МОЛОДЕЖНАЯ НАУКА КАК ФАКТОР И РЕСУРС

Понятие культура употребляется в научной литературе, публицистике, в повседневной жизни. Это один из наиболее часто встречаемых терминов. На сегодняшний день существует более 500 трактовок этого понятия. Основные значения культуры это: совокупность материальных и духовных ценностей, созданных человечеством и сам процесс их создания и использования (в самом широком понимании); совокупность произведенных человеком духовных богатств и ценностей (в менее широком понимании); только как художественная культура, как образная художественная объективация (в узком понимании).

У людей разных обществ присутствуют разные культуры. Они отличаются друг от друга традициями, ценностями, навыками, а также мировоззрением, мироощущением, мироосознанием. В последнее время в экономической, политической, технической и социальной сферах, произошли серьезные сдвиги в культурных основах современного общества. Изменились стимулы, ценности. Всё больше появилось противоречий, которые становятся причинами политических конфликтов, экономических и территориальных претензий.

Изменения в людях происходят постепенно и не сразу заметно. У старшего поколения дольше сохраняются традиционные ценности и нормы советского государства, в отличие от молодежи. Молодёжь обладает мобильностью, пластична, либеральна, с очевидностью вступает в конфликт с консервативным поколением «отцов», в результате чего происходит трансформация духовных ценностей.

Переломным моментом в культуре нашей страны является начало 90-х гг. прошлого столетия. В это время происходил ускоренный распад единой культуры СССР. Ценности культуры Советского Союза стали неприемлемы для сепаратизма национальных культур. Нарастала напряженность и сильнейшее противостояние. Итогом всего происходящего стал распад единого социокультурного пространства. Система, органически связанная историей страны, оказалась совершенно в новой политической и экономической ситуации. Кардинально поменялось многое, а так же взаимоотношения властей и культур. Государство потеряло возможность диктовать свои условия, идеократия рухнула, в результате чего культура была лишена гарантированного заказчика в лице диктатуры власти.

Так пропала основа партократической культуры, а вместе с ней и тех моральных основ формирования высоконравственного строителя коммунизма. 
Дальнейший путь духовного развития был предметом горячих споров. Существовало много количества вариантов, но общая культурная идея отсутствовала. Итогом стал очевидный факт, почти за тридцатилетний период новой России (с момента принятия последней Конституции) мы наблюдаем культурный сдвиг.

Политическая система свободного общества с помощью СМИ вносит хаос в духовные ориентации граждан. Всё больше пропагандируется насилие, безнравственность, безответственность, социальное иждивенчество, пренебрежение работой, профессией, браком и семьей. Вызывает беспокойство в обществе многие центральные телепередачи, в темах которых осуществляется духовно-нравственное развращение людей, из-за чего происходит зомбирование всех социальных групп населения, конечно в первую очередь молодежи.

Молодые люди разочарованы, в них растет ощущение безнадежности и бесперспективности, они не верят в возможность преодоления экономических, политических и социальных проблем. К разрушению моральных устоев и приводит невозможность достижения определенных высоких материальных ориентиров. Появляется иллюзия правового беззакония. Закон пока остаётся единственным сдерживающим фактором. Все это приводит к культурному сдвигу, ускоряя процесс дисгармонии человеческого в человеке.

В области искусства самым зрелищным остаётся киноискусство, вытесняется театральное искусство, литература. В настоящее время количество театров увеличивается, но число зрителей в них уменьшается. Это говорит о том, что театр чужд людям, а ведь в классических постановках прививались истинные ценности добра. Сегодня в кино и на театральной сцене говорят и показывают о том, о чем раньше не было принято, и даже самой мысли не допускалось нести на сцену или экран. «Диспропорция, сложившаяся в культуре, не безобидна, особенно если она принимает затянувшийся характер и люди, родившиеся после ее возникновения, уже не знают иной культуры. Она проявляет агрессивность по отношению к иным формам проявления культуры. Устойчивый и длительный характер такой альтернативности приводит к вырыванию из культуры ее основ в виде системы общечеловеческих ценностей и интересов. Причем эта ситуация не исключает возможности формально стоять и на позициях высокой культуры, 


\section{МОЛОДЕЖНАЯ НАУКА КАК ФАКТОР И РЕСУРС

замыкая ее в элитарных образцах, а значит уменьшая возможности ее восприятия большим числом людей» [3, с. 40].

Практицизм и индивидуализм - вот разрушительные основы современной культуры. Современный человек не желает понимать, что самоотдача и коллективизм делает человеческое общество обществом. Новое поколение испытывает жажду жить за счёт других, не понимая, что не могут все одновременно, мечтая об этом, так жить, рушится основа человеческого общества. «Самым важным ... становится господство идеи антикультурности как таковой, что на уровне индивидуального поведения реализуется как феномен «неприятия другого»: другого поведения, другой музыки, другой прически, другого человека в целом» [4, с. 231]. Это суть каждого дня, которая «не всегда явно, но всегда внутренне отталкивает от себя любые подлинные ценности культуры и тогда, когда они растворены в обиходе молодежного общения, и тогда, когда они сосредоточены в консерваториях, музеях, произведениях искусства» [2, с. 52].

Не лучшая ситуация обстоит с библиотеками. В России неуклонно сокращается количество библиотек, хотя наша страна была самой читающей в мире. Современная молодежь мало читает художественную литературу, поэтому роль книги в культуре постепенно теряет свое значение. Молодые люди не испытывают духовного трепета от произведений классики. Все их время занимают электронные средства. Интернет, где основной целью является развлечение. В результате процесса создания информационного общества возросла роль технологической культуры, которая вытесняет духовную культуру. Обращаясь к содержанию преобразовательной деятельности человека, надо понимать, что естественный природный мир приспособлен к нуждам и потребностям человека. Создана культурная среда, в которую входят техника, жилища, средства общения, связи, сообщения, предметы быта, произведения искусства и определённая культура общественного сожительства. Под технологической культурой следует понимать такую преобразовательную деятельность человека во всех сферах жизни, когда главным критерием жизни становится степень применения новых технологий и технологических процессов.

Технологические тенденции постепенно проникают во все сферы деятельности человека. Из-за огромного количества информации происходят изменения в системе образования, в изобразительном искусстве, в архитектуре и музыке, в театре и музее, в функционирование библиотек. 


\section{МОЛОДЕЖНАЯ НАУКА КАК ФАКТОР И РЕСУРС \\ ОПЕРЕЖАЮЩЕГО РАЗВИТИЯ}

Общество должно больше уделять внимания духовной культуре, одновременно повышая уровень технической культуры.

«Научно-технический прогресс не принесет счастья, если не будет дополняться чрезвычайно глубокими изменениями в социальной, нравственной и культурной жизни человечества. Внутреннюю духовную жизнь людей, внутренние импульсы их активности трудней всего прогнозировать, но именно от этого зависит в конечном итоге и гибель, и спасение цивилизации... Человечеству угрожает упадок личной и государственной морали, проявляющегося уже сейчас в глубоком распаде во многих странах основных идеалов права и законности, в потребительском эгоизме, во всеобщем росте уголовных тенденций, в ставшем международным бедствием националистическом и политическом терроризме, в разрушительном распространении алкоголизма и наркомании ... Все же мне кажется, что наиболее глубокая первичная причина лежит во внутренней бездуховности...» [6, с. 74]. Необходимо оптимизировать взаимоотношения между духовной и технологической культурой, надо понять, как обеспечить гармоничное взаимодействие человека и природы, человека и общества, человека и человека.

Коммерция, ещё одна болезнь современного общества, ее результат бездуховность. «Наша культура подверглась коммерциализации, в том числе и русский классический театр, за редким исключением (театры Дорониной и Губенко). Попраны заветы великого русского драматурга А. Островского, который утверждал: «Театр может быть не чем иным, как школой нравов... Спекуляция образцового русского театра не выстроит. Она ищет скорой наживы, быстрого обогащения... В театре буржуазия горячо сочувствует лишь пошлым намекам и остроумию самого низкого сорта». В стране господствуют примитивные, бездуховные массовые культуры и шоу-бизнес. Поэтому не сочиняются русские по духу песни, не выпускаются патриотические кинокартины, как в советское время» [1, с.4].

Религиозный аспект современной культуры рассматривается как спасительный для духовного развития общества. Религия «выполняет важные мировоззренческие, нравственные, коммуникативные функции...церковные иерархи, могли бы многое сделать для укрепления духовных основ жизни российского общества, если бы они больше были повернуты не к власти, а к народу, не к наращиванию имущественных и земельных богатств, а к реальным земным болевым проблемам жизни миллионов россиян, если бы 
они последовательно выступали за преодоление разрыва между богатыми и бедными, за обеспечение большей социальной справедливости, за укрепление духовности и нравственности у людей и в их взаимоотношениях и т.д.» $[5$, с. 108$]$.

Мир находится в вечном движении, постоянно меняется. Вместе с ним меняется культура народа, понимание места и значимости среди многочисленных культур планеты. Стремление к прогрессу, изменения политического строя неминуемо приводит к культурным сдвигам. Россия не исключение, а скорее логическое продолжение глобального культурного сдвига человеческой цивилизации.

\section{Список литературы}

1. Анучкин - Тимофеев А. Всплеск дурновкусия // Советская Россия. 2014. - №82(14030) - С. 4.

2. Кнабе Г. С. Диалектика повседневности // Материалы к лекциям по общей теории культуры и культуре античного Рима. М., 1993. -527 с.

3. Миронов В.В. Коммунистическое пространство как фактор трансформации современной культуры и философии // Вопросы философии. 2006. - №2. - С. 39-40.

4. Миронов В. В. Философия. Учебник. - М.: «ПРОСПЕКТ», 1998. 240 c.

5. Осинский И.И. Особенности развития российской культуры в современных условиях // Вестник бурятского государственного университета. - 2014. - № 14(1). - C.104-108.

6. Сахаров А.Д. Тревога и надежда. — 2-е изд. - М .: «Интер- Версо», 1991. - 336 c.

(C) В.С. Полотнянко, Л.Н. Тедеева, 2021 